\title{
EHMTI-0335. Depression and anxiety symptoms in patients suffering from new daily persistent headache. A prospective, controlled study
}

\author{
C Deligianni*, DD Mitsikostas \\ From 4th European Headache and Migraine Trust International Congress: EHMTIC 2014 \\ Copenhagen, Denmark. 18-21 September 2014
}

\section{Introduction}

New Daily Persistent Headache (NDPH) is a chronic primary headache with uncertain outcome. Comorbities may play important role in choosing the right treatment in order to improve the management of this disorder.

\section{Aim}

To investigate the comorbidity of depression or anxiety of the patients suffering from NDPH.

\section{Methods}

One hundred and forty four (144) headache outpatients (62 men and 82 women) and one hundred and fifty (150) healthy controls (56 men and 94 women) were screened prospectively using a questionnaire that included the Hamilton scales for both Anxiety and Depression.

\section{Results}

The mean scores of both HAM-A and HAM-D scales were significantly higher in NDPH patients $(19 \pm 7.3$ and $16 \pm 6.3$ respectively) comparing with the healthy population $(6.8 \pm 4.0$ and $5.7 \pm 3.3$ respectively, $\mathrm{p}<0.05$ for both comparisons). No significant difference was detected in the Hamilton scaling scores between NDPH and Chronic Tension Type Headache sufferers.

\section{Conclusion}

NDPH sufferers showed more depression or anxiety symptoms than healthy controls, as headache sufferers from chronic TTH. Treating properly psychiatric comorbities in NDPH sufferers, or choosing drugs that influence both conditions simultaneously may improve outcome.
No conflict of interest.

Published: 18 September 2014

doi:10.1186/1129-2377-15-S1-C15

Cite this article as: Deligianni and Mitsikostas: EHMTI-0335. Depression and anxiety symptoms in patients suffering from new daily persistent headache. A prospective, controlled study. The Journal of Headache and Pain 2014 15(Suppl 1):C15.
Submit your manuscript to a SpringerOpen ${ }^{\bullet}$ journal and benefit from:

- Convenient online submission

- Rigorous peer review

- Immediate publication on acceptance

- Open access: articles freely available online

- High visibility within the field

Retaining the copyright to your article

Submit your next manuscript at $>$ springeropen.com

\section{SpringerOpen ${ }^{\circ}$}

(C) 2014 Deligianni and Mitsikostas; licensee Springer. This is an Open Access article distributed under the terms of the Creative Commons Attribution License (http://creativecommons.org/licenses/by/2.0), which permits unrestricted use, distribution, and reproduction in any medium, provided the original work is properly cited. 